\title{
Conversion surgery for stage IV gastric cancer
}

\author{
Satoshi Ida, Masayuki Watanabe \\ Department of Gastroenterological Surgery, Cancer Institute Hospital of Japanese Foundation for Cancer Research, Tokyo 135- \\ 8550, Japan.
}

Correspondence to: Dr. Satoshi Ida, Department of Gastroenterological Surgery, Cancer Institute Hospital of Japanese Foundation for Cancer Research, 3-8-31, Ariake, Koto, Tokyo 135-8550, Japan. E-mail: satoshi.ida@jfcr.or.jp

\begin{abstract}
How to cite this article: Ida S, Watanabe M. Conversion surgery for stage IV gastric cancer. J Cancer Metastasis Treat2018;4:22. http://dx.doi.org/10.20517/2394-4722.2017.75
\end{abstract}

Received: 21 Nov 2017 First Decision: 18 Jan 2018 Revised: 20 Apr 2018 Accepted: 23 Apr 2018 Published: 16 May 2018

Science Editor: Lucio Miele Copy Editor: Jun-Yao Li Production Editor: Cai-Hong Wang

\begin{abstract}
Gastric cancer with distant metastases, such as para-aortic lymph node metastases, hepatic metastases, and peritoneal dissemination, is classified as stage IV. In this situation, cancer cells have formed micrometastases throughout the body; therefore, according to the algorithm of the Japanese guidelines, stage IV cancer is outside the indication for curative resection. Recent advances in some chemical agents have been remarkable, and some patients have survived for long periods even with stage IV gastric cancer. Thus, even in patients with stage IV gastric cancer, there is a possibility that gastrectomy as conversion surgery could play an important role in the treatment strategy. Gastrectomy as conversion therapy can be safely conducted without perioperative mortality and is considered a sufficiently acceptable treatment strategy. However, the significance of conversion surgery for stage IV gastric cancer remains controversial. In this review, we summarize the treatment strategies and outcomes of conversion surgery for stage IV gastric cancer.
\end{abstract}

Keywords: Gastric cancer, stage IV, gastrectomy, conversion surgery, outcome

\section{INTRODUCTION}

Gastric cancer is a highly malignant tumor that can metastasize at high rates by lymphogenous spread, hematogenous spread, and dissemination. In stage IV advanced gastric cancer, which is characterized by distant metastasis to sites other than regional lymph nodes, cancer cells are considered to have formed micrometastases throughout the body. Such cancer is outside the indication for curative resection. As stated in the Japanese treatment guidelines, chemotherapy remains the main therapeutic approach for stage IV gastric cancer, and surgery for these patients is usually confined to palliative resection or a bypass operation to relieve symptoms ${ }^{[1]}$. The European Society for Medical Oncology (ESMO) ${ }^{[2]}$ and the National Comprehensive

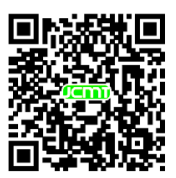


Cancer Network $(\mathrm{NCCN})^{[3]}$ guidelines for gastric cancer also recommended the doublet or triplet platinum/ fluoropyrimidine combinations for metastatic gastric cancer as a palliative chemotherapy.

Recent advances in chemotherapy and molecular targeted therapy have been remarkable, and some patients have survived for long periods. Some of these patients include those who have successfully undergone curative resection after chemotherapy. However, the significance of surgical resection after chemotherapy, termed conversion surgery, remains controversial for patients with gastric cancer.

Factors that make curative resection impossible include tumor invasion to adjacent structures (T4b), extensive nodal disease (para-aortic and/or bulky lymphnode metastasis located on supra-pancreatic area), hepatic metastases, peritoneal dissemination, peritoneal cytology positive for cancer cells, and other metastatic disease. The treatment strategies and outcomes differ according to each noncurative factor. In this chapter, we review the treatment outcome of conversion surgery for each type of unresectable advanced gastric cancer.

\section{TREATMENT STRATEGIES AND OUTCOMES FOR CONVERSION SURGERY Lymph node metastases}

Para-aortic lymph node metastases from gastric cancer are classified as M1, and surgery with curative intent is not indicated according to the treatment algorithm of the current guidelines ${ }^{[1]}$. In addition, a standard treatment strategy including a role for para-aortic lymph node dissection (PAND) in patients with more advanced nodal disease has not yet been established. Systemic PAND was attempted in clinical studies in Japan until its survival benefit was denied in a randomized trial in which only patients without lymph node swelling in the para-aortic region were eligible ${ }^{[4]}$. Based on the results of that study, prophylactic PAND for patients with no signs of para-aortic lymph node metastasis was discontinued. However, no prospective study has either supported or opposed PAND in patients with surgically resectable para-aortic lymph node metastases at station numbers 16a2-b1.

Tokunaga et al..$^{[5]}$ retrospectively analyzed 178 patients who underwent Ro resection and were found to have metastasis to the para-aortic lymph nodes after examination of the resected specimens. Of these patients, 50 were treated by D2 gastrectomy plus PAND and 128 were treated by D2 with sampling of para-aortic nodes that were suspected to have cancer involvement. The 3 -year survival rate was $21 \%$. Perioperative chemotherapy was administered at the physicians' discretion but was not consistently delivered throughout the series. The authors concluded that D2 gastrectomy + PAND could be beneficial for carefully selected patients with metastasis to the para-aortic lymph nodes.

The effectiveness of PAND for patients with para-aortic lymph node metastases was shown in phase II trial by the Japan Clinical Oncology Group (JCOG) (JCOG0405). The treatment strategy was as follows. Two courses of neoadjuvant chemotherapy with S-1 plus cisplatin followed by gastrectomy with D2 plus PAND were performed. Patients with bulky nodal disease with or without lymphadenopathy restricted to the station No. 16a2-b1 region were eligible. Peritoneal metastasis was ruled out and the CY1 status was determined by staging laparoscopy prior to registration. The trial showed favorable results: a curative resection rate of $82 \%$ and 3 - and 5-year overall survival (OS) rates of 59\% and 53\%, respectively ${ }^{[6]}$. Therefore, this treatment strategy could be recommended for institutions with sufficient expertise in PAND.

Another phase II trial exploring multimodal treatment for patients with para-aortic lymph node metastases limited to stations No. 16a2-b1 was performed in China. This study employed a combination of capecitabine and oxaliplatin (XELOX) as induction chemotherapy. In total, 48 patients were enrolled. After a median of 4 cycles of chemotherapy, 28 of the 48 patients (58.3\%) underwent conversion surgery. The median OS of 
all patients was 29.8 months, although these premature data were calculated after a median follow-up time of only 12.4 months. However, only D2 lymph node dissection was performed in that study; the fact that PAND was not performed should be considered ${ }^{[7]}$. The authors' strategy was to convert chemotherapy to surgical therapy for selected responders in the hope that up to six cycles of chemotherapy might cure the cancers outside the confines of standard surgical dissection. In contrast, the Japanese investigators treated patients by neoadjuvant chemotherapy to eliminate micrometastases that may or may not have been present, followed by surgery with curative intent to dissect all cancerous tissues that had been detected prior to the treatment. Therefore, the philosophy behind the two strategies is quite different.

Whether the preoperative diagnosis of para-aor tic lymph node metastasis is reliable must be considered when discussing these treatment options. Lymph node metastasis is currently diagnosed when the lymph node diameter shows either a minor axis of $\geq 8 \mathrm{~mm}$ or major axis of $\geq 10 \mathrm{~mm}$ on abdominal computed tomography (CT). The JCOG 1302A trial, which evaluated the accuracy of clinical diagnosis and pathological stage III gastric cancer, showed that the sensitivity and specificity of the CT criteria for nodal metastasis were $62.5 \%$ (505/808) and 65.7\% (278/423), respectively ${ }^{[8]}$. A recent prospective study indicated that multidetector-row CT achieved relatively high overall accuracy $(76 \%)$ in preoperative detection of nodal metastasis ${ }^{[9]}$. Furthermore, Marrelli et al.$^{[10]}$ reported that the sensitivity and specificity of multidetector-row CT in detecting para-aortic lymph node metastasis were encouragingly high at $85 \%$ and $95 \%$, respectively. Improvements in diagnostic accuracy also contribute to improvements in diagnostic modality.

\section{Liver metastases}

Colorectal liver metastases are widely considered targets of surgery with curative intent because they often present as liver-only diseases, and Ro resection showed favorable survival in a recent clinical study ${ }^{[11]}$. However, the necessity of surgical resection of liver metastases of gastric cancer is still controversial.

The guidelines do not recommend surgery for stage IV gastric cancer; therefore, most patients with liver metastases of gastric cancer receive systemic therapy ${ }^{[1]}$. In contrast, several studies have shown that long-term survival can be obtained by performing hepatectomy for liver metastases of gastric cancer. However, only retrospective analyses of small cohorts collected over several decades have been performed, and most were single-institution studies. No prospective trial exploring the benefits of hepatectomy has been conducted.

We reviewed the 7 largest studies reported from 2012 to 2017, each with $\geq 50$ patients who underwent hepatectomy for liver metastases from gastric cancer ${ }^{[12-17]}$ [Table 1]. In these series, the 3- and 5-year OS rates were $14.0 \%$ to $51.4 \%$ and $9.3 \%$ to $42.3 \%$, respectively, with a median survival time (MST) of 13.0 to 40.8 month $^{[12-18]}$. Solitary metastasis or a small number of metastatic nodules was highlighted as a favorable prognosis in most of the studies. After multivariate analysis, Oki et al ${ }^{[16]}$ reported that more than two liver metastases [hazard ratio (HR), 2.14; 95\% confidence interval (CI), 1.16-3.97] and Kinoshita et al. ${ }^{[13]}$ reported that three or more liver metastases are independent factors that is associated with worse prognosis (HR, 2.33; 95\% CI, 1.62-3.36). Oki et al. ${ }^{[16]}$ also reported that the presence of three or more lymph node metastases was a factor that is associated with worse prognosis. Moreover, a size of $\geq 3 \mathrm{~cm}^{[15]}$ or $\geq 5 \mathrm{~cm}^{[12,13]}$ or serosal invasion ${ }^{[12,13,18]}$ have been reported as an independent risk factors for the primary gastric cancer itself.

However, these reports were the results of accumulation of cases over a long period of 10 to 20 years. Therefore, with the given the recent advances in imaging studies, it is possible that the diagnosis of the number of liver metastasis might not be reliable. Thus, hepatectomy may be considered for patients with a small number of metastatic nodules and not restricted to a solitary tumor, provided that no other noncurative factor is present. At present, it may be reasonable to keep the indication for hepatectomy when a patient has three or fewer metastases. 
Table 1. Literature overview of outcomes following hepatectomy for gastric cancer liver metastases

\begin{tabular}{lllccccc}
\hline Ref. & Year & Country & $\begin{array}{c}\text { Study } \\
\text { interval }\end{array}$ & $\begin{array}{c}\text { No. of } \\
\text { patients }\end{array}$ & 3-year OS & 5-year OS & $\begin{array}{c}\text { MST } \\
\text { (months) }\end{array}$ \\
\hline Takemura et al. ${ }^{[12]}$ & 2012 & Japan & $1993-2011$ & 64 & 50.0 & 37.0 & 34.0 \\
Kinoshita et al. ${ }^{[13]}$ & 2015 & Japan & $1990-2010$ & 256 & 41.9 & 31.1 & 31.1 \\
Tiberio et al. ${ }^{[14]}$ & 2015 & Italy & $1997-2011$ & 53 & 14.0 & 9.3 & 13.0 \\
Oki et al. ${ }^{[16]}$ & 2016 & Japan & $2000-2010$ & 94 & 51.4 & 42.3 & 40.8 \\
Tiberio et al. ${ }^{[18]}$ & 2016 & Italy & $1990-2013$ & 105 & 20.3 & 13.1 & 14.6 \\
Guner et al. ${ }^{[15]}$ & 2016 & South Korea & $1998-2013$ & 68 & 40.6 & 30.0 & 24.0 \\
Song et al. ${ }^{17]}$ & 2017 & China & $2001-2012$ & 96 & 47.6 & 21.7 & 34.0 \\
\hline
\end{tabular}

OS: overall survival; MST: median survival time

Although chemotherapy has been successful and surgical cases are increasing, there is no evidence for the recommended chemotherapy regimen in this particular situation. Therefore, systemic chemotherapy is performed with reference to the treatment recommended by the guidelines ${ }^{[1]}$. However, Tiberio et al ${ }^{[18]}$ reported that adjuvant chemotherapy was a prognostic factor. Therefore, adjuvant chemotherapy after hepatectomy will be discussed as increasingly more cases are accumulated.

\section{Peritoneal dissemination}

The peritoneum is a frequent site for metastases in patients with advanced gastric cancer, and peritoneal dissemination is one of the most important life-threatening factors in such patients. Systemic chemotherapy is administered to patients with peritoneal dissemination as well as other patients with stage IV gastric cancer. Systemic chemotherapy for gastric cancer has steadily progressed in recent years, and 5-fluorouracilbased or cisplatin-based regimens are generally accepted as possible standard chemotherapy. However, an adequate therapeutic effect has not been obtained. Otherwise, the treatment strategy for patients with only positive peritoneal cytology remains controversial. The Japanese Gastric Cancer Association advocates classification of free cancer cells in the peritoneal cavityas M1, and surgery with curative intentis not indicated according to the treatment algorithm of the current guidelines. However, the guidelines suggest that a cytology-positive status in the absence of other noncurative factors (i.e., macroscopic disease) can be managed with D2 gastrectomy and perioperative chemotherapy ${ }^{[1]}$.

Intraperitoneal (i.p.) chemotherapy has recently been conducted to improve the treatment outcomes for peritoneal dissemination. Ishigami et al. ${ }^{[19]}$ developed a regimen involving the addition of weekly i.p. paclitaxel (PTX) to an established systemic chemotherapy regimen of S-1 and intravenous PTX for the treatment of peritoneal metastasis of gastric cancer. The i.p. PTX was administered to enhance antitumor activity against peritoneal metastasis by maintaining a high concentration of the drug in the peritoneal cavity over a long period, and its clinical effects have been verified by several convincing clinical trials involving patients with ovarian cancer with peritoneal metastasis ${ }^{[20]}$. In a phase II trial conducted by Ishigami et al ${ }^{[21]}$, 40 patients with gastric cancer that was positive for peritoneal metastases and/or peritoneal cy tology were enrolled. The authors reported a 1-year OS rate of $78 \%$. In addition, malignant ascites disappeared or decreased in 13 of 21 (62\%) patients, and cancer cells detected by peritoneal cytology diminished in 24 of 28 (86\%) patients. In a phase III trial comparing this i.p. chemotherapy to S-1 plus cisplatin (PHOENIX-GC trial), the primary analysis did not show the statistical superiority of the i.p. regimen $(P=0.08$; HR, 0.72; 95\% CI, 0.49-1.04), however, prolongation of the MST by 2.5 months was recognized in the i.p. group, and the i.p. chemotherapy could thus be considered a promising treatment option ${ }^{[22]}$. Furthermore, Ishigami et al ${ }^{[23]}$ performed a retrospective study of 100 cases of $\mathrm{P} 1$ and/or CY1 gastric cancer and found that conversion surgery was performed in 64 patients, among whom Ro resection was performed in $44(69 \%)$.

Table 2 shows the promising results of several phase II clinical trials of i.p. taxanes after 2010. In these series, the 1-year OS rates were $69 \%$ to $78 \%$, with an MST of 16.2 to 24.6 months ${ }^{[2,24-27]}$. Notably, the possibility of negative peritoneal cytology was very high at $81.8 \%$ to $97.0 \%$. 
Table 2. Phase II clinical trials with intraperitoneal taxanes for gastric cancer with peritoneal disease

\begin{tabular}{|c|c|c|c|c|c|}
\hline Ref. & Year & No. of patients & 1-year OS & MST (months) & Turned negative for cytology (\%) \\
\hline Ishigami et al..$^{[21]}$ & 2010 & 40 & 78.0 & 22.6 & $24 / 28(86)$ \\
\hline Fujiwara et al. ${ }^{[24]}$ & 2012 & 18 & 76.0 & 24.6 & - \\
\hline Imano et $\left.a\right|_{.} ^{[25]}$ & 2012 & 35 & 66.7 & 21.3 & - \\
\hline Fushida et $a / .{ }^{[26]}$ & 2013 & 27 & 70.4 & 16.2 & $18 / 22(81.8)$ \\
\hline Yamaguchi et al. ${ }^{[27]}$ & 2013 & 35 & 77.1 & 17.6 & $28 / 29(97)$ \\
\hline
\end{tabular}

OS: overall survival; MST: median survival time

Staging laparoscopy may be useful for the evaluation of resectability after chemotherapy. Several societies have provided recommendations for staging laparoscopy in patients with advanced gastric cancer ${ }^{[1,2]}$. If information on the CY status is available prior to surgery, a chemotherapy-first strategy can be taken, whereby only patients whose cytology status turns negative are indicated for surgery. To verify the effect of preoperative chemotherapy on positive cytology, Jamel et al ${ }^{[28]}$ reviewed studies in which staging laparoscopy was performed. Pooled analysis demonstrated that positive cytology was associated with significantly reduced OS (HR, 3.46; 95\% CI, 2.77-4.31; $P<0.0001$ ). Interestingly, negative cytology following neoadjuvant chemotherapy was associated with significantly improved OS (HR, 0.42; 95\% CI, 0.31-0.57; $P<0.0001$ ). The absence of macroscopic peritoneal disease with positive cytology was associated with significantly improved OS (HR, 0.64; 95\% CI, 0.56-0.73; $P<0.0001$ ). This study suggests that patients with initial positive cytology may have a good prognosis following neoadjuvant treatment if the cytology results become negative after treatment.

Yoshida et al. ${ }^{[29]}$ proposed new categories for the classification of stage IV gastric cancer that focused on the biology and heterogeneous characteristics of stage IV gastric cancer. They divided cancers based on the absence (categories 1 and 2) or presence (categories 3 and 4) of macroscopically detectable peritoneal dissemination, the biological outcome of which differs from that of hematological metastasis. Using this classification, Yamaguchi et al. ${ }^{[30]}$ performed a retrospective study to clarify the role of conversion surgery in the treatment of stage IV cancer. Even in patients with macroscopic peritoneal dissemination without other organ metastasis (category 3), the survival of those who underwent conversion surgery was prolonged (31.0 months), and even the MST of those who failed to undergo conversion surgery was relatively good (18.5 months). However, patients with involvement of other organs in addition to peritoneal disease (classified as category 4; noncurable metastasis) understandably had fewer chances for surgical intervention, and their MST was 10 months.

\section{Postoperative complications}

Kubota et al..$^{[31]}$ reported that postoperative complications that cause prolonged inflammation have an obvious impact on not only OS but also disease-specific mortality of patients with gastric cancer, even if the tumor is curatively resected. Thus, when performing conversion surgery, it is necessary to perform safe gastrectomy that does not cause complications.

Gastrectomy as conversion therapy can be safely conducted without perioperative mortality. The reported incidence of postoperative complications after gastrectomy is $24 \%$ to $29 \%^{[30,32]}$, which is similar to that in patients undergoing conventional radical surgery for gastric cancer (20.9\% in patients with D2 lymph node dissection and $28.1 \%$ in patients undergoing an extended operation with aortic lymph node dissection) $(\text { JCOG9501) })^{[33]}$.

\section{Predictive factors for long-term outcome}

Several reports have described the long-term outcomes of conversion surgery for stage IV gastric cancer. In various studies, the prognosis of patients who underwent conversion surgery was significantly better than that 
of patients who did not undergo conversion surgery ${ }^{[30,32,34,35]}$. Furthermore, whether Ro resection is performed may greatly affect the prognosis. Yamaguchi et al. ${ }^{[30]}$ analyzed the treatment outcomes of 259 patients with stage IV gastric cancer and found that the MST of those who underwent Ro resection (41.3 months) was significantly better than that of patients who underwent R1 and R2 resection (21.2 months). Sato et al. ${ }^{[32]}$ evaluated the treatment outcomes of initially unresectable gastric cancer treated with docetaxel, cisplatin, and S-1 (DCS) chemotherapy in a clinical trial. Conversion therapy was achieved in 33 of 100 patients (33\%), and Ro resection was performed in $28(84.8 \%)$ patients. The authors focused on the pathological response of the primary tumor, and the pathological response rate was $78.8 \%$. Furthermore, multivariate analysis showed that pathological response was the only independent prognostic factor for conversion therapy $(P=0.009)$. These findings suggest the clinical significance of performing conversion surgery for stage IV gastric cancer.

\section{VOLUME REDUCTION SURGERY}

The JCOG and Korea Gastric Cancer Association conducted an open-label, randomized phase III trial (JCOG0705/KGCA01) comparing gastrectomy plus chemotherapy vs. chemotherapy alone in patients with advanced gastric cancer with a single noncurative factor. The patients were randomly assigned to gastrectomy followed by chemotherapy or chemotherapy alone. The chemotherapy regimen was S-1 plus cisplatin, which is a standard treatment for advanced gastric cancer. The 2-year OS rate was 31.7\% (95\% CI, 21.7-42.2) for patients assigned to chemotherapy alone compared with $25.1 \%$ (95\% CI, 16.2-34.9) for those assigned to gastrectomy plus chemotherapy. The median OS was 16.6 months (95\% CI, 13.7-19.8) for patients assigned to chemotherapy alone and 14.3 months (95\% CI, 11.8-16.3) for those assigned to gastrectomy plus chemotherapy (HR, 1.09; 95\% $\mathrm{CI}$, 0.78-1.52; $P=0.70$ ). Thus, no evidence in support of volume reduction surgery was found for patients with advanced gastric cancer, even those with a single noncurative factor ${ }^{[36]}$.

The German AIO study group conducted the RENAISSANCE (AIO-FLOT5) trial: effect of chemotherapy alone $v s$. chemotherapy followed by surgical resection on survival and quality of life in patients with limited metastatic adenocarcinoma of the stomach or esophagogastric junction. This trial is a prospective, multicenter, randomized, investigator-initiated phase III trial aimed to evaluate the effects of perioperative chemotherapy with FLOT (5-flourouracil, leucovorin, oxaliplatin, and docetaxel) in chemo naive patients with limited metastatic disease ${ }^{[37]}$. If the RENAISSANCE concept proves to be effective, this could potentially lead to a new standard therapy for metastatic gastric cancer.

\section{CONCLUSION}

Long-term survivors exist among patients who have undergone conversion surgery with Ro resection for stage IV gastric cancer. Adequate selection of patients with stage IV gastric cancer for conversion therapy is very important to increase the likelihood of long-term survival. Furthermore, even with surgery, the prognosis of patients with other involvement of other organs in addition to peritoneal dissemination is poor. Therefore, surgical intervention in such patients should be performed cautiously. Further cooperation of specialists, such as surgeons and physicians, is necessary to allow for the establishment of diagnostic methods, surgery with fewer complications, and development of more effective agents. In the future, an approach applying the concept of conversion surgery might expand the eligibility for surgery with curative intent to include even patients with currently considered unresectable for metastases.

\section{DECLARATIONS}

\section{Authors' contributions}

Concept, design, literature search and manuscript preparation: Ida S

Manuscript editing and review: Watanabe $\mathrm{M}$ 


\section{Financial support and sponsorship}

None.

\section{Conflicts of interest}

Authors declare that they have no conflicts of interest.

\section{Patient consent}

Not applicable.

\section{Ethics approval}

Not applicable.

\section{Copyright}

(c) The Author(s) 2018.

\section{REFERENCES}

1. Japanese Gastric Cancer Association. Japanese gastric cancer treatment guidelines 2014 (ver. 4). Gastric Cancer 2017;20:1-19.

2. Smyth EC, Verheij M, Allum W, Cunningham D, Cervantes A, Arnold D; ESMO Guidelines Committee. Gastric cancer: ESMO Clinical Practice Guidelines for diagnosis, treatment and follow-up. Ann Oncol 2016;27:v38-49.

3. Ajani JA, D’Amico TA, Almhanna K, Bentrem DJ, Chao J, Das P, Denlinger CS, Fanta P, Farjah F, Fuchs CS, Gerdes H, Gibson M, Glasgow RE, Hayman JA, Hochwald S, Hofstetter WL, Ilson DH, Jaroszewski D, Johung KL, Keswani RN, Kleinberg LR, Korn WM, Leong S, Linn C, Lockhart AC, Ly QP, Mulcahy MF, Orringer MB, Perry KA, Poultsides GA, Scott WJ, Strong VE, Washington MK, Weksler B, Willett CG, Wright CD, Zelman D, McMillian N, Sundar H. Gastric Cancer, Version 3.2016, NCCN Clinical Practice Guidelines in Oncology. J Natl Compr Canc Netw 2016;14:v1286-312.

4. Sasako M, Sano T, Yamamoto S, Kurokawa Y, Nashimoto A, Kurita A, Hiratsuka M, Tsujinaka T, Kinoshita T, Arai K, Yamamura Y, Okajima K. D2 lymphadenectomy alone or with para-aortic nodal dissection for gastric cancer. $N$ Engl J Med 2008;359:453-62.

5. Tokunaga M, Ohyama S, Hiki N, Fukunaga T, Aikou S, Yamaguchi T. Can superextended lymph node dissection be justified for gastric cancer with pathologically positive para-aortic lymph nodes? Ann Surg Oncol 2010;17:2031-6.

6. Tsuburaya A, Mizusawa J, Tanaka Y, Fukushima N, Nashimoto A, Sasako M. Neoadjuvant chemotherapy with S-1 and cisplatin followed by D2 gastrectomy with para-aortic lymph node dissection for gastric cancer with extensive lymph node metastasis. Br J Surg 2014;101:653-60.

7. Wang Y, Yu YY, Li W, Feng Y, Hou J, Ji Y, Sun YH, Shen KT, Shen ZB, Qin XY, Liu TS. A phase II trial of Xeloda and oxaliplatin (XELOX) neo-adjuvant chemotherapy followed by surgery for advanced gastric cancer patients with para-aortic lymph node metastasis. Cancer Chemother Pharmacol 2014;73:1155-61.

8. Fukagawa T, Katai H, Mizusawa J, Nakamura K, Sano T, Terashima M, Ito S, Yoshikawa T, Fukushima N, Kawachi Y, Kinoshita T, Kimura Y, Yabusaki H, Nishida Y, Iwasaki Y, Lee SW, Yasuda T, Sasako M. A prospective multi-institutional validity study to evaluate the accuracy of clinical diagnosis of pathological stage III gastric cancer (JCOG1302A). Gastric Cancer 2018;21:68-73.

9. Hasegawa S, Yoshikawa T, Shirai J, Fujikawa H, Cho H, Doiuchi T, Yoshida T, Sato T, Oshima T, Yukawa N, Rino Y, Masuda M, Tsuburaya A. A prospective validation study to diagnose serosal invasion and nodal metastases of gastric cancer by multidetector-row CT. Ann Surg Oncol 2013;20:2016-22.

10. Marrelli D, Mazzei MA, Pedrazzani C, Di Martino M, Vindigni C, Corso G, Morelli E, Volterrani L, Roviello F. High accuracy of multislices computed tomography (MSCT) for para-aortic lymph node metastases from gastric cancer: a prospective single-center study. Ann Surg Oncol 2011;18:2265-72.

11. Folprecht G, Gruenberger T, Bechstein W, Raab HR, Weitz J, Lordick F, Hartmann, JT, Stoehlmacher-Williams J, Lang H, Trarbach T, Liersch T, Ockert D, Jaeger D, Steger U, Suedhoff T, Rentsch A, Kohne CH. Survival of patients with initially unresectable colorectal liver metastases treated with FOLFOX/cetuximab or FOLFIRI/cetuximab in a multidisciplinary concept (CELIM study). Ann Oncol 2014;25:1018-25.

12. Takemura N, Saiura A, Koga R, Arita J, Yoshioka R, Ono Y, Hiki N, Sano T, Yamamoto J, Kokudo N, Yamaguchi T. Long-term outcomes after surgical resection for gastric cancer liver metastasis: an analysis of 64 macroscopically complete resections. Langenbecks Arch Surg 2012;397:951-7.

13. Kinoshita T, Kinoshita T, Saiura A, Esaki M, Sakamoto H, Yamanaka T. Multicentre analysis of long-term outcome after surgical resection for gastric cancer liver metastases. Br J Surg 2015;102:102-7.

14. Tiberio GA, Baiocchi GL, Morgagni P, Marrelli D, Marchet A, Cipollari C, Graziosi L, Ministrini S, Vittimberga G, Donini A, Nitti D, Roviello F, Coniglio A, de Manzoni G. Gastric cancer and synchronous hepatic metastases: is it possible to recognize candidates to R0 resection? Ann Surg Oncol 2015;22:589-96. 
15. Guner A, Son T, Cho I, Kwon IG, An JY, Kim HI, Cheong JH, Noh SH, Hyung WJ. Liver-directed treatments for liver metastasis from gastric adenocarcinoma: comparison between liver resection and radiofrequency ablation. Gastric Cancer 2016;19:951-60.

16. Oki E, Tokunaga S, Emi Y, Kusumoto T, Yamamoto M, Fukuzawa K, Takahashi I, Ishigami S, Tsuji A, Higashi H, Nakamura T, Saeki H, Shirabe K, Kakeji Y, Sakai K, Baba H, Nishimaki T, Natsugoe S, Maehara Y. Surgical treatment of liver metastasis of gastric cancer: a retrospective multicenter cohort study (KSCC1302). Gastric Cancer 2016;19:968-76.

17. Song A, Zhang X, Yu F, Li D, Shao W, Zhou Y. Surgical resection for hepatic metastasis from gastric cancer: a multi- institution study. Oncotarget 2017;8:71147-53.

18. Tiberio GA, Ministrini S, Gardini A, Marrelli D, Marchet A, Cipollari C, Graziosi L, Pedrazzani C, Baiocchi GL, La Barba G, Roviello F, Donini A, de Manzoni G. Factors influencing survival after hepatectomy for metastases from gastric cancer. Eur J Surg Oncol 2016;42:1229-35.

19. Ishigami H, Kitayama J, Otani K, Kamei T, Soma D, Miyato H, Yamashita H, Hidemura A, Kaisaki S, Nagawa H. Phase I pharmacokinetic study of weekly intravenous and intraperitoneal paclitaxel combined with S-1 for advanced gastric cancer. Oncology 2009;76:311-4.

20. Markman M, Brady MF, Spirtos NM, Hanjani P, Rubin SC. Phase II trial of intraperitoneal paclitaxel in carcinoma of the ovary, tube, and peritoneum: a Gynecologic Oncology Group Study. J Clin Oncol 1998;16:2620-4.

21. Ishigami H, Kitayama J, Kaisaki S, Hidemura A, Kato M, Otani K, Kamei T, Soma D, Miyato H, Yamashita H, Nagawa H. Phase II study of weekly intravenous and intraperitoneal paclitaxel combined with S-1 for advanced gastric cancer with peritoneal metastasis. Ann Oncol 2010;21:67-70.

22. Ishigami H, Fujiwara Y, Fukushima R, Nashimoto A, Yabusaki H, Imamoto H. Phase III study of intraperitoneal paclitaxel plus S-1/ paclitaxel compared with S-1/cisplatin in gastric cancer patients with peritoneal metastasis: PHOENIX-GC trial. J Clin Oncol 2016;34 suppl 15:abstr4014.

23. Ishigami H, Yamaguchi H, Yamashita H, Asakage M, Kitayama J. Surgery after intraperitoneal and systemic chemotherapy for gastric cancer with peritoneal metastasis or positive peritoneal cytology findings. Gastric Cancer 2017;20:128-34.

24. Fujiwara Y, Takiguchi S, Nakajima K, Miyata H, Yamasaki M, Kurokawa Y, Mori M, Doki Y. Intraperitoneal docetaxel combined with S-1 for advanced gastric cancer with peritoneal dissemination. J Surg Oncol 2012;105:38-42.

25. Imano M, Peng YF, Itoh T, Nishikawa M, Satou T, Yasuda A, Inoue K, Kato H, Shinkai M, Tsubaki M, Yasuda T, Imamoto H, Nishida S, Furukawa H, Takeyama Y, Okuno K, Shiozaki H. A preliminary study of single intraperitoneal administration of paclitaxel followed by sequential systemic chemotherapy with S-1 plus paclitaxel for advanced gastric cancer with peritoneal metastasis. Anticancer Res 2012;32:4071-5.

26. Fushida S, Kinoshita J, Kaji M, Hirono Y, Goda F, Yagi Y, Oyama K, Sudo Y, Watanabe Y, Fujimura T. Phase I/II study of intraperitoneal docetaxel plus S-1 for the gastric cancer patients with peritoneal carcinomatosis. Cancer Chemother Pharmacol 2013;71:1265-72.

27. Yamaguchi H, Kitayama J, Ishigami H, Emoto S, Yamashita H, Watanabe T. A phase 2 trial of intravenous and intraperitoneal paclitaxel combined with S-1 for treatment of gastric cancer with macroscopic peritoneal metastasis. Cancer 2013;119:3354-8.

28. Jamel S, Markar SR, Malietzis G, Acharya A, Athanasiou T, Hanna GB. Prognostic significance of peritoneal lavage cytology in staging gastric cancer: systematic review and meta-analysis. Gastric Cancer 2018;21:10-8.

29. Yoshida K, Yamaguchi K, Okumura N, Tanahashi T, Kodera Y. Is conversion therapy possible in stage IV gastric cancer: the proposal of new biological categories of classification. Gastric Cancer 2016;19:329-38.

30. Yamaguchi K, Yoshida K, Tanahashi T, Takahashi T, Matsuhashi N, Tanaka Y, Tanabe K, Ohdan H. The long-term survival of stage IV gastric cancer patients with conversion therapy. Gastric Cancer 2018;21:315-23.

31. Kubota T, Hiki N, Sano T, Nomura S, Nunobe S, Kumagai K, Aikou S, Watanabe R, Kosuga T, Yamaguchi T. Prognostic significance of complications after curative surgery for gastric cancer. Ann Surg Oncol 2014;21:891-8.

32. Sato Y, Ohnuma H, Nobuoka T, Hirakawa M, Sagawa T, Fujikawa K, Takahashi Y, Shinya M, Katsuki S, Takahashi M, Maeda M, Okagawa Y, Naoki U, Kikuchi S, Okamoto K, Miyamoto H, Shimada M, Takemasa I, Kato J, Takayama T. Conversion therapy for inoperable advanced gastric cancer patients by docetaxel, cisplatin, and S-1 (DCS) chemotherapy: a multi-institutional retrospective study. Gastric Cancer 2017;20:517-26.

33. Sano T, Sasako M, Yamamoto S, Nashimoto A, Kurita A, Hiratsuka M, Tsujinaka T, Kinoshita T, Arai K, Yamamura Y, Okajima K. Gastric cancer surgery: morbidity and mortality results from a prospective randomized controlled trial comparing D2 and extended paraaortic lymphadenectomy--Japan Clinical Oncology Group study 9501. J Clin Oncol 2004;22:2767-73.

34. Yoshida M, Ohtsu A, Boku N, Miyata Y, Shirao K, Shimada Y, Hyodo I, Koizumi W, Kurihara M, Yoshida S, Yamamoto S. Long-term survival and prognostic factors in patients with metastatic gastric cancers treated with chemotherapy in the Japan Clinical Oncology Group (JCOG) study. Jpn J Clin Oncol 2004;34:654-9.

35. Takahari D, Boku N, Mizusawa J, Takashima A, Yamada Y, Yoshino T, Yamazaki K, Koizumi W, Fukase K, Yamaguchi K, Goto M, Nishina T, Tamura T, Tsuji A, Ohtsu A. Determination of prognostic factors in Japanese patients with advanced gastric cancer using the data from a randomized controlled trial, Japan clinical oncology group 9912. Oncologist 2014;19:358-66.

36. Fujitani K, Yang HK, Mizusawa J, Kim YW, Terashima M, Han SU, Iwasaki Y, Hyung WJ, Takagane A, Park DJ, Yoshikawa T, Hahn S, Nakamura K, Park CH, Kurokawa Y, Bang YJ, Park BJ, Sasako M, Tsujinaka T. Gastrectomy plus chemotherapy versus chemotherapy alone for advanced gastric cancer with a single non-curable factor (REGATTA): a phase 3, randomised controlled trial. Lancet Oncol 2016;17:309-18.

37. Al-Batran SE, Goetze TO, Mueller DW, Vogel A, Winkler M, Lorenzen S, Novotny A, Pauligk C, Homann N, Jungbluth T, Reissfelder 
C, Caca K, Retter S, Horndasch E, Gumpp J, Bolling C, Fuchs KH, Blau W, Padberg W, Pohl M, Wunsch A, Michl P, Mannes F, Schwarzbach M, Schmalenberg H, Hohaus M, Scholz C, Benckert C, Knorrenschild JR, Kanngießer V, Zander T, Alakus H, Hofheinz RD, Roedel C, Shah MA, Sasako M, Lorenz D, Izbicki J, Bechstein WO, Lang H, Moenig SP. The RENAISSANCE (AIO-FLOT5) trial: effect of chemotherapy alone vs. chemotherapy followed by surgical resection on survival and quality of life in patients with limited-metastatic adenocarcinoma of the stomach or esophagogastric junction - a phase III trial of the German AIO/CAO-V/CAOGI. BMC Cancer 2017;17:893. 